\title{
Perder y ganar suicidios: teorías vilamatasianas del espacio literario
}

Partiendo de uno de los postulados de Historia abreviada de la literatura portátil, según el cual el suicidio debe perpetrarse en el espacio de la escritura, este artículo analiza Suicidios ejemplares (1991) de Enrique VilaMatas examinando cómo dicha propuesta se vincula con la teoría literaria y cómo se relaciona con el espacio y el texto. La obra, además de explorar la senda del exterminio de la escritura y su equiparación con el acto suicida, escenifica una suerte de teoría literaria que reclama la importancia de lo espacial en la literatura y la necesidad de que esta, desprovista del transcurrir temporal característico del discurso, se aproxime a la ucronía propia de las artes plásticas.

Palabras claves: Enrique Vila-Matas, suicidio, teoría literaria, espacio, espíritu apolíneo

This article analyzes Enrique Vila-Matas's Suicidios ejemplares (1991). Building on one of A Brief History of Portable Literature's premises, that suicide be perpetrated within the literary sphere, I examine how this idea is linked to literary theory and how it relates to both space and text. In addition to exploring the notion of the death of writing and suicide as its counterpart, Suicidios ejemplares illustrates a type of literary theory that underlines the importance of space in literature and, given that it is not bound by the passage of time typical of discourse, proposes that literature move toward the uchronia of the visual arts.

Keywords: Enrique Vila-Matas, suicide, literary theory, space, Apollonian principle

Se tuer, c'est prendre une mort pour l'autre, c'est une sorte de bizarre jeu de mots Maurice Blanchot, L'espace littéraire

Dilemme. De deux choses l'une : ne pas parler, ne pas se taire. Suicide Jacques Rigaut, Papiers posthumes 
Señalaban con acierto los organizadores del Congreso Internacional Géographies du Vertige dans l'ouvre d'Enrique Vila-Matas, celebrado en Perpignan en marzo de 20I2, la necesidad de pasar a estudiar las formas y las funciones del espacio en los textos vilamatasianos, dejando atrás los tradicionales temas de aproximación a su obra (la impostura, la intertextualidad), ya suficientemente explotados por la crítica, para atender así a "la evidente predominancia del elemento espacial frente al temporal" en su obra (Garcia II). Dicha precisión y enfoque se revelan más que pertinentes, habida cuenta de la relevancia que la poética del espacio tiene en el conjunto de su obra, y de lo poco que, hasta ese encuentro, se había trabajado. En este artículo abordaremos la repercusión textual del fenómeno suicida tal y como se postula en Historia abreviada de la literatura portátil (1985) - el suicidio perpetrado en el espacio de la escritura -, examinando cómo dicha propuesta se vincula con la teoría literaria, repercute en el lenguaje y se relaciona con el espacio y con el texto. Para ello recurriremos, en lo esencial, al volumen de relatos de Enrique Vila-Matas, Suicidios ejemplares (I99I), donde los vínculos entre la auto-aniquilación y el silencio de la escritura no son tan evidentes, pero suponen una interesante puesta en escena de una peculiar poética del espacio, explicitada en esa declaración de intenciones que constituye el prefacio: "Mi idea, al iniciar este libro contra la vida extraña y hostil, es obrar de forma parecida a la del vagabundo de Fez, es decir, intentar orientarme en el laberinto del suicidio a base de marcar el itinerario de mi propio mapa secreto y literario" (7).

Si la escritura, tal y como lo establece Platón en el Fedro y nos recuerda Emilio Lledó en El silencio de la escritura, es una forma de fijar la memoria, de atestiguar la vida, así sea mediante una escritura ficticia, entonces no escribir se corresponde con no haber vivido, una suerte de anulación del ser. Entre dejar de escribir y el suicidio surge un hilo conector que se afianza si recordamos un fragmento de Historia abreviada de la literatura portátil (1985): "Realizar el suicidio en el espacio mismo de la escritura. Lo que nació siendo un comentario irónico acabó convirtiéndose en un principio aceptado por todos los miembros de la sociedad secreta. Y quedó bien claro que, en adelante, el suicidio sólo podría ser realizable sobre el papel" (36). La pregunta que surge a partir de lo leído es obvia, ¿cómo acontece el suicidio sobre el papel? Y la respuesta, nos la ofrece también el texto: "recurriendo al silencio más radical, o bien convirtiéndose uno mismo en personaje literario, o traicionando al lenguaje mismo" (37). La muerte y el silencio de la escritura vienen, así, de la mano. Tal y como está planteada en Bartleby y compañía (2000), la escritura del no, en última instancia, implica una resistencia - así sea mínima - a la fatalidad e invoca, en un susurro, a la vida. ${ }^{\text {E }}$ En este texto 
Vila-Matas indagaba las razones de los escritores ágrafos (de nacimiento o por advenimiento), en cuya actitud subyace a menudo una única certeza: la de que toda escritura es prescindible. De ahí las dudas acerca de la validez de las palabras; la página rasgada o tachada, o simplemente no esbozada, será la consecuencia de dicha (in)seguridad. Marcelo, el jorobado y solitario oficinista cuya voz nos guía en la novela lleva veinticinco años sin publicar, aquejado del mal de Bartleby, "el mal endémico de las letras contemporáneas, la pulsión negativa o la atracción por la nada que hace que ciertos creadores, aun teniendo una conciencia literaria muy exigente (o quizás precisamente por eso), no lleguen a escribir nunca" (I2). Puesto que la escritura es una forma de escapar a la muerte, dejar voluntariamente de escribir implica dejarse atrapar por ella, en una suerte de suicidio: "Cesser d'écrire implique de faire le deuil de l'infini, d'accepter de prononcer les derniers mots d'une œuvre où résonnent les derniers mots d'une vie" (Eymar, "Les derniers"). Y, sin embargo, Marcelo opta por excluir de su lista a los suicidas reales, aquellos que no se enfrentan en exclusiva al suicidio textual, aunque habrá algunas excepciones, como la de Jacques Vaché, que se convertiría a finales de la segunda década del siglo $\mathrm{XX}$ en uno de los mitos fundadores (Livak) para los suicidas dadaístas y surrealistas:

"El arte es una estupidez", dijo Jacques Vaché, y se mató, eligió la vía rápida para convertirse en artista del silencio. En este libro no va a haber mucho espacio para bartlebys suicidas, no me interesan demasiado, pues pienso que en la muerte por propia mano faltan los matices, las sutiles invenciones de otros artistas - el juego, a fin de cuentas, siempre más imaginativo que el disparo en la sien - cuando les llega la hora de justificar su silencio. (Vila-Matas, Bartleby 74)

Esa gradación descendente en la narrativa vilamatasiana, en lo que toca a la aniquilación de la escritura, culmina en Doctor Pasavento (2005) con la desaparición del sujeto escribiente, en lo que supone una vuelta de tuerca al manido tópico de la muerte del autor. Frente a la escasez de bartlebys, Fernando Rodríguez de la Flor proponía en un ensayo de 1997 el biblioclasmo como arma contra la logorrea incontenible, el exceso de producción tipográfica, que caracterizaría la época en que vivimos. Aunque en El mal de Montano (2002) se presenta al joven Montano como el autor de una novela sobre los escritores que habían dejado de escribir - y se recuperan algunas de las figuras emblemáticas de Bartleby y compañía, como la del citado Jacques Vaché -, Fernando Valls ha querido ver justamente en ese texto el reverso de Bartleby y compañía, la incitación al biblioclasmo, la escritura "contra aquellos que escriben sin venir a cuento" (302). La presencia del escritor se había visto mermada con la apología 
minimalista de Historia abreviada de la literatura portátil e inmolada en la aventura bartlebyana. En Doctor Pasavento su supresión acaba con toda posibilidad escrituraria, en un escribir para ausentarse que es el reverso justo del deseo de perdurabilidad:

Comencé a decirme que para acceder a la simple existencia literaria, para luchar contra esta invisibilidad que desde el principio les amenaza, los escritores tienen que crear las condiciones de su aparición, es decir, de su visibilidad literaria. Pero me dije también - existe la maniobra contraria y ésta es mucho más difícil. Teniendo como objetivo el camino inverso (el de recuperar su invisibilidad) algunos escritores, como creo que es mi caso en estos momentos, emprenden la dificultosa tarea de ir creando una escritura secreta al tiempo que van organizando silenciosamente las condiciones de su desaparición, esas que habrán de permitirles un día desarmar esa visibilidad que sienten que cada vez les corroe más, pues socava gravemente su relación con la dignidad y lucidez del silencio. (Vila-Matas, Pasavento 255-256)

Los microgramas de Robert Walser - una escritura microscópica con vocación de inexistencia, hecha, además, a lápiz, con lo que queda subvertida toda perennidad - son la metáfora perfecta de la inquietud de Vila-Matas. Pero en Doctor Pasavento la paradoja la constituye el hecho de que la desaparición del escritor no vaya acompañada del esperable mutismo, sino que lleva como séquito un inagotable torrente verbal. Esto contraviene, aunque tan solo en apariencia, el deseo de anulación. En ese escribir para poder morir de raigambre kafkiano-blanchotiana (Blanchot II5), la escritura sufre un desplazamiento en la ficción, proyectándose desde el sujeto que tiende a desaparecer hacia las diversas máscaras o personalidades construidas en derredor suyo. La desaparición, esencia de la literatura, se gesta entonces con palabras y se proyecta como una amenaza sobre lo real, como la rue Vaneau sobre Pasavento.

Pero, como adelantábamos, los Suicidios ejemplares, más que explorar la senda del exterminio de la escritura y su equiparación con el acto suicida, vienen a escenificar una suerte de teoría literaria, a partir del motivo del suicidio, que defiende la primacía del espíritu apolíneo del arte en los procesos de la imaginación creadora, en detrimento del principio dionisiaco, tal y como los describió Friedrich Nietzsche en El nacimiento de la tragedia. ${ }^{2}$ Es cierto que la actitud silente constituye el acto apolíneo por excelencia y que es el punto de llegada de Orfeo, una de las figuras míticas que encarnan el triunfo de Apolo sobre Dionisos, tras ser descuartizado; ese silencio órfico entroncaría con la alternativa de los vanguardistas entre el completo silencio y la tentación de escribir. Tanto dadaístas como surrealistas verían en el silencio radical que comporta el suicidio, ora una 
forma de rechazo del arte, ora la culminación de la propia obra, una vez aniquiladas las fronteras entre obra de arte y artista. De modo que, aunque a primera vista pueda parecer que no hay demasiada continuidad entre Suicidios ejemplares y el resto de obras mencionadas de Vila-Matas, donde se intensifica la presencia blanchotiana - mediada siempre por la ironía -, podemos encontrarla, en parte, gracias a esa lectura que proponemos aquí. 3 Veremos que el libro se resiste a una aproximación al suicidio en clave meramente existencial, aunque no la niega por completo (es, de hecho, la propuesta de Florencia Zaldívar, que también analiza en su ensayo la novela Lejos de Veracruz, o la de Alvarado Silva y Hernández Juárez, a propósito de "Muerte por saudade"), lo que lo alejaría, por ejemplo, de los textos de Juan Carlos Onetti, tal y como los ha leído Catalina Quesada Gómez ("Absurdamente"), mientras que lo aproxima al modo de proceder de un autor como Ricardo Piglia, quien coloca en sus textos a diversos suicidas que siempre tienen sus propias teorías (sobre el suicidio o sobre la escritura) y quien recurre al suicidio como elemento inextricablemente vinculado al texto, propiciando así que "los suicidios piglianos siempre conllev[e]n repercusiones textuales" (Quesada Gómez, "Asesinos" 233).4 Esta circunstancia, desde luego, dificulta las interpretaciones de la obra vilamatasiana que partan de presupuestos sociológicos, antropológicos o psiquiátricos, desde el momento en que la cuestión temática queda ampliamente trascendida para mostrar el suicidio en su dimensión textual, proyectándolo sobre el acto mismo de la escritura. 5

Es cierto que no resulta inviable un primer nivel de lectura que considere muchos de los suicidios de la obra, no tanto como una huida de la vida, sino más bien como una vía de escape hacia otra dimensión, siguiendo una de las respuestas atribuidas a Antonin Artaud en Historia abreviada de la literatura portátil, al ser preguntado por su opinión acerca de quitarse la vida:

Pero, ¿qué pensaría usted de un suicidio anterior, un suicidio que nos hiciera regresar, pero al otro lado de la existencia, y no del lado de la muerte? Sólo eso tendría valor para mí. No le tengo apetito a la muerte, yo siento el apetito del no ser, de nunca haber caído en ese reducto de imbecilidades de abdicaciones, de renuncias y de obtusos encuentros... (Vila-Matas, Historia 37 )

Se trataría, de esa forma, de buscar en la literatura una forma de enfrentarse al taedium vitae y de escamotear así la muerte autoinfligida; de perder suicidios, como aventura el texto preliminar. 0 también de emplear el pensamiento suicida como terapia contra el suicidio, como una experiencia vicaria - como la misma ficción - que termina sustituyendo el 
tan temido y definitivo paso hacia el otro lado por parte de los personajes. Es justamente eso lo que sugiere la narradora de "Un invento muy práctico", quien afirma no solo haber encontrado en la escritura "la fórmula mágica que podía hacer[le] soportable la vida (II3), sino también haber sido capaz de crear un personaje de ficción - fruto, acaso, de su locura - que se suicide por ella cada vez que lo necesite. Curiosamente, los textos de Vila-Matas, lejos de insistir en el tradicional vínculo entre enajenación y suicidio, hacen un uso peculiar de dicha circunstancia, con frecuencia mediante narradores poco fiables, para equiparar los desvaríos del loco con los actos de la imaginación creadora, como acontece en "Un invento muy práctico". En ese sentido, se podría también hablar de un claro vitalismo en muchos de los relatos, en los que se asiste a una exaltación de la vida, bien mediante la ridiculización del acto suicida, bien gracias a su traslado a otro nivel diegético. ${ }^{6}$ Junto con su marcado antirrealismo, el hecho de que gran parte de los suicidas potenciales que hay en el libro sean los narradores en primera persona de sus extravagantes y disparatados relatos, mostrando en los mismos que, o bien no son de fiar, o bien no están del todo en sus cabales, ayuda a evitar la identificación por parte del lector y se consigue presentar, así, el suicidio como una opción remota y no como una opción real, como acontece en "Me dicen que diga quién soy", donde a lo anterior se suma un estilo insufrible que imposibilita cualquier tipo de empatía con el narrador. El humor y la ironía constantes hacen, además, ver el suicidio como un acontecimiento festivo que, más que conducir a la muerte, puede llevar a su (no) ejecutor a una vida más plena, en una nueva forma de afrontar la consideración vanguardista del acto suicida como evasión y no como autodestrucción.

No existen, pues, juicios o reproches de índole moral para con los suicidas en los textos de Enrique Vila-Matas. Como ha visto Marcos Eymar ("Les derniers"), el sentimiento religioso está ausente en el tratamiento de la muerte en sus obras y, más bien, habría que mirar a la Roma clásica para encontrar un modelo ético. Así, es posible establecer una filiación en lo que concierne a la muerte, en general, y al suicidio, en particular, tanto con el mundo clásico, por un lado, como, por otro, con el Romanticismo, cuya influencia le llegaría al autor, indirectamente, a través de las vanguardias. Esto resulta tanto más cierto en el relato "Las noches del iris negro", cuyo epígrafe es una cita de las Cartas morales a Lucilio, de Séneca, y que constituye un claro homenaje al mundo clásico. Los epitafios que los personajes van leyendo en Port del Vent reflejan la moral pagana ante la muerte voluntaria, que resulta aceptable cuando ya no se quiere seguir viviendo y se impone una cierta dignidad. Aunque resulta imposible establecer un único modo de entender el suicidio en la antigua Roma, la presencia en el relato de un personaje llamado Catón - que, 
paradójicamente, no tiene el valor de alcanzar la muerte por propia mano - evoca sin lugar a dudas la idea del suicidio como máximo ejemplo de la libertad integral del hombre: "Refus héroïque d'asservissement, sa mort s'inscrivit dans les esprits comme l'apothéose de la liberté la plus authentique : celle qu'on paie au prix de la vie" (Grisé 203). Una libertad y un modo de aceptar la muerte autoinfligida que se hace extensiva al resto de los suicidas del libro, sobre los cuales no se proyecta enjuiciamiento ni reprobación algunos, como ha sido frecuente en el mundo occidental en los pasados siglos (Minois II), ni la consideración de que se trata de enfermos (Andrés 318).

Eymar ("Les derniers") apunta igualmente al peso del Romanticismo en lo tocante a la concepción de la relación autor/obra y en cómo se entiende la muerte autoinfligida, elegida en un acto de libertad máxima y ejecutada como un auténtico arte, tal y como lo proclama el personaje de "Un invento muy práctico": "Barrymore dice que morir es todo un arte (y solo un arte) y que él lo hace excepcionalmente bien" (I25). Esa presencia del Romanticismo tamizado por la vanguardia es incluso más evidente en Historia abreviada de la literatura portátil, en concreto en el capítulo titulado "Suicidios de hotel", donde la figura del dadaísta Jacques Rigaut se presenta dispuesta a encarnar al perfecto suicida romántico: joven, impetuoso y capaz de inventarse un enamoramiento no correspondido para poder abrazar el suicidio tras su descalabro amoroso, no sin antes fundar su Agence générale du suicide. En parte como los románticos, tanto los surrealistas como los dadaístas utilizaron el suicidio como una figura de evasión de la realidad, de la sociedad y de las convenciones morales y lo convirtieron en un leitmotiv de sus obras, como una nueva forma de épater le bourgeois, cuando no lo pusieron ellos mismos en práctica, como forma de vivir (y no solo escribir) su propio poema (Livak 245). Pero a diferencia del Rigaut de la versión vilamatasiana, el real proclamaría la necesidad de que el suicidio no poseyera causa alguna, es decir, que se tratase de un acto gratuito (Livak 252) además de una auténtica vocación, que pareciera un acto fortuito y que, en la medida de lo posible, se presentara como una broma macabra (249). En la tergiversación a que somete Vila-Matas en su texto a muchos de los personajes y acontecimientos reales, resulta interesante cómo los integrantes de la conjura shandy se apartan del regusto de los auténticos surrealistas y dadaístas franceses por el suicidio, que llegaron a convertirlo en un auténtico mito e, incluso, en un lugar común en sus textos. Justamente por haberse convertido en un lugar común entre los vanguardistas franceses de entreguerras, el suicidio quedó en ocasiones reducido a un conjunto de situaciones clichés y a una retórica manida, fácilmente ridiculizable (254). Y va a ser esa veta ridiculizadora la que Vila-Matas explote en muchos de los relatos de 
Suicidios ejemplares, siendo tal vez el caso más claro el del artista de "El coleccionista de tempestades", a cuyo suicidio, largamente planeado y preparado para culminar - en la onda vanguardista - una obra perfecta, se le anticipa, burlona, la muerte por infarto.

Es incluso factible abordar la lectura del texto analizando los múltiples tópicos sobre los suicidas a partir de los cuales la obra se erige y de los cuales, en la mayoría de los casos, se distancia, gracias a la estrategia de la ironía. Así, Julie M. Dahl ha estudiado las imágenes construidas en España acerca de Portugal como un lugar propicio para planear un suicidio, mencionando como ejemplo destacado el uso que Vila-Matas hace de Lisboa en el primero de los relatos de Suicidios ejemplares - y que volverá a utilizar en el relato "Porque ella no lo pidió", de Exploradores del abismo (215-276). Los ejemplos se suceden en la obra, como acontece con el tópico del suicidio perpetrado como consecuencia de un amor no correspondido, en "Los amores que duran toda una vida", o el taedium vitae, en "Las noches del iris negro", aunque siempre con salidas un tanto inesperadas que implican un tour de force con respecto a dichos tópicos. Sin embargo, aun siendo todas estas interpretaciones sobre el suicidio en la obra de VilaMatas legítimas y plausibles, pretendemos demostrar que un segundo o tercer nivel de lectura nos revela, igualmente, la elaboración en sus textos de una propuesta poética en torno a la autoaniquilación, que ahonda en cuestiones de índole literaria y que trasciende la mera presencia de un tema. En ese sentido nos parece acertada la consideración de Cristina Oñoro Otero, para quien el suicidio en esta obra ha de ser entendido como una posibilidad para los personajes de desplazarse por los distintos niveles narrativos e incidir así en aspectos metaficcionales: "no es tanto una puerta de salida, como una entrada por la que acceder al mundo de la ficción. Funciona como un umbral entre distintos mundos diegéticos, lo que remarca el carácter artificioso de la literatura" (Enrique I27).

El acercamiento a Suicidios ejemplares exige, en primer lugar, de un análisis del texto que lo abre, "Viajar, perder países", que actúa de prefacio. En él un narrador cuya voz se arroga el papel de autor sienta las bases de lo que será esa colección de relatos en torno al suicidio que nos disponemos a leer, ofreciéndonos una carta de navegación o de lectura. Destaca aquí la utilización del mapa, presentado primero como recurso para orientarse en lo extraño y hostil (en el caso del vagabundo de Fez), y después como proyección para trazar la geografía personal, a partir de la interpretación antropocéntrica de la geografía física, tal y como la concibiera Opicinus de Canistris a principios del siglo XIV. Si a eso añadimos la cita del loco de principios de siglo ("Viajo para conocer mi geografía") y el hecho de que Vila-Matas haya desplazado la cita original a los muros de un manicomio, cuando en la fuente de donde lo toma aparece 
como el último de los versos del poema de un loco, vislumbramos con cierta claridad la vocación espacial que ostenta esta escritura. En el último capítulo de la Historia abreviada de la literatura portátil, "Un shandy dibuja el mapa de su vida", se nos da la cita "Je voyage pour connaître ma géographie", mencionando la proveniencia: "Anotación de un loco, recogida por Manuel Réja en L'art chez les fous, París, I907" (II7).7 Pero Marcel Réja (y no Manuel), en ningún momento habla de pintura mural, sino que analiza el poema de un loco. El motivo del mapa como proyección de la geografía personal - si bien allí no cita a Opicimus - está ya en dicho capítulo, por lo que enlaza con el prólogo de los Suicidios ejemplares, libro que, entendemos, ha de ser leído como continuación de aquel. El motivo de la locura, por otro lado, vincula a ambos personajes y puede ser tomado como clave de lectura. ${ }^{8}$

Lo mismo cabría decir de la mención a la Melancolía hermética de Savinio. Ahí asistimos a un nuevo desplazamiento o atribución errónea (del pintor Giorgio Chirico a su hermano, justamente en su dimensión de escritor y no en la de pintor), que desvía lo pictórico hacia lo escriturario, o más bien, dota a la escritura de la espacialidad de la pintura. De este modo, el dice que se atribuye a Savinio y el relato de la historia de este suicida romano es en realidad un pinta y la historia abreviada de lo que le aconteció al romano, presentada en su linealidad discursiva, se concreta en el espacio pictórico (espacio textual). La expresión a grandes rasgos que utiliza el narrador se vuelve, por tanto dilógica. Por su parte, la cita de Jacques Rigaut, tomada de sus Papiers posthumes ("Essayez, si vous le pouvez, d'arrêter un homme qui voyage avec son suicide à la boutonnière"), vincula nuevamente los Suicidios ejemplares con la Historia abreviada de la literatura portátil, donde el creador de la Agence générale $d u$ suicide adquiría, con todas las desviaciones necesarias, la categoría de personaje. Sus textos, fagocitados por el de Vila-Matas, servirán allí, convenientemente atribuidos a otros personajes, de breviario suicida. $9 \mathrm{La}$ frase de Rigaut aparece aquí colocada estratégicamente en el centro de esa cebolla que es el prólogo, donde mapas y dibujos envuelven al romano suicida de la Melancolía hermética que, a su vez, rodea con sus brazos al de Rigaut, aquel que marcha con la flor suicida en la solapa. ${ }^{\text {Io }}$

Existe, por tanto, en el prefacio, un afán por concebir la escritura en su dimensión espacial, vinculándola con la pintura mural y el grafiti, el trazado de mapas o la pintura surrealista. No es casualidad que la vanguardia sea aquí invocada."I De hecho, la imagen ilógica u onírica de cuño surrealista, así como el humor de esa tradición vanguardista en la que Vila-Matas se sitúa, aparecerán a lo largo de todo el libro, ofreciendo el suicidio, a la manera de Rigaut, desde las perspectivas más disparatadas: desde ese pobre diablo que, en "Me dicen que diga quién soy", decide 
suicidarse haciéndose cosquillas hasta morir, al personaje que dice matarse por vergüenza histórica en "Los amores que duran toda una vida", pasando por el protagonista de "En busca de la pareja eléctrica", que concluye su relato cuando se dispone a ingerir estricnina para alcanzar a su compañero en la muerte y, así, iniciar juntos una gira como cómicos por el espacio sideral. ${ }^{.2}$ Frente a la temporalidad del discurso y, en cierto modo, de la lectura, la propuesta del prólogo remite a la propuesta shandy de realizar el suicidio en el espacio mismo de la escritura. Ahí radica la ejemplaridad de estos suicidios: ${ }^{33}$ no solo en su carácter artístico, como afirma con acierto Álvaro Enrigue (84) o en su condición de tratado de suicidiología (Masoliver Ródenas 88), sino sobre todo en su espacialidad y acronía, en la propuesta del suicidio en su dimensión clásica y serena. Coincide en esto Vila-Matas con otra abanderada tardía de la vanguardia, la poeta argentina Alejandra Pizarnik, que en el segundo tercio del siglo XX puso en práctica su obsesión poética por encarnarse en el espacio de la escritura (Quesada Gómez, "Escenografías" 49).

En cuanto al texto que ejerce de epílogo o colofón, se trata de la reescritura de un fragmento de una de las últimas cartas de Mario de SáCarneiro a Fernando Pessoa titulado, "Pero no hagamos ya más literatura", en la que le anuncia su suicidio (que no se perpetraría en realidad sino veintiséis días después). La leve modificación introducida por Vila-Matas con respecto al original (Mas não façamos literatura) resulta más que significativa y remite a la propuesta literaria de Bartleby y compañía. La distancia se acentúa, por ejemplo, en la traducción francesa (Suicides exemplaires, Christian Bourgois, I995), donde el "Mais en voilà assez avec la littérature" recuerda lejanamente al "Mais ne faisons pas de littérature" de la versión francesa de las cartas (De Sá-Carneiro, Poésies 300). ${ }^{14} i$ Ha de ser leído, entonces, como palinodia de lo anterior, de lo enunciado en el prólogo y en los diez relatos?, ¿como invitación a abandonar el espacio literario para dirigirnos a la sórdida realidad de lo real? Si nos limitamos a su contenido, quizás; y aun así, nos encontraríamos ante el oxímoron del decir el silencio, de vociferar el fin de la literatura en la obra literaria misma. Pero si lo consideramos en su condición genérica - en tanto que carta de suicida -, el texto supone una variante de lo que lo precede, desde el momento en que el suicidio se teje en el papel, en el espacio, todavía, de la escritura. El propio escritor, en esa misma carta, alude a dicha vinculación genérica:

A menos dum milagre na próxima 2. ${ }^{a}$-feira 3 (ou mesmo na véspera) o seu Mário de Sá-Carneiro tomará uma forte dose de estricnina e desaparecerá deste mundo. É assim tal e qual - mas custa-me tanto a escrever esta carta pelo ridículo que sempre encontrei nas "cartas de despedida"... Não vale a pena lastimar-me, meu 
querido Fernando: afinal tenho o que quero: o que tanto sempre quis - e eu, em verdade, já não fazia nada por aqui... Já dera o que tinha a dar. (De Sá-Carneiro, Cartas 279-280)

Que la realidad viniera tiempo después a concederle estatus de anuncio a la misiva es algo meramente accesorio, como bien explora la argentina Vlady Kociancich en "Cuando leas esta carta", publicado poco después de Suicidios ejemplares. En los siete relatos que componen Cuando leas esta carta (1998) sobrevuela, de un modo u otro, el leitmotiv suicida. "La mujer de Liñares", "El guardián de La Residencia”, "Ojos negros", “Alma en pena”, "Idiomas", "La noche de la gitana" y "Cuando leas esta carta" constituyen, por así decirlo, sendas variaciones en torno al suicidio. Además de como motivo, tomado en su dimensión existencial (a la manera de "Alma en pena"), la autora ahonda en la dimensión textual del fenómeno, en el vínculo con la escritura, con el lenguaje. El ejemplo máximo lo encontramos en el relato "Cuando leas esta carta", gracias a ese particular subgénero, cuasi epistolar, que son las cartas del suicida. Como vimos, VilaMatas invierte la dinámica de dicho subgénero en el relato "Un invento muy práctico", por cuanto la carta de la narradora viene justamente a anunciar que no se suicida gracias al poder de la escritura y a la creación de personajes de ficción (que también podrían no ser más que fruto de su locura), en particular, del personaje de Barrymore, sobre el que metaficcionalmente proyecta su propio suicidio.

El anuncio del fin de la literatura (de su suicidio) y su deseable conversión hacia lo pictórico, hacia la inmovilidad temporal, se convierte en uno de los leitmotivs argumentales de Suicidios ejemplares. Así, el narrador de "Muerte por saudade", pintor incapaz y narrador - según parece, por obligación, además de poco fiable -, se enfrenta a la lucha de la abolición del tiempo de la historia para poder plasmarla en el cuadro. Su incapacidad de trasladar el ritmo de los pies de la mendiga, aquella contadora de historias a la que le sobra todo el tiempo del mundo marca la talla de su fracaso:

Así que la recuerdo, la recuerdo muy bien, pero nunca he podido acabar de pintarla. Ella se me escapa siempre con su ritmo antiguo en pies descalzos, y tal vez por eso (pues no encuentro otra explicación a esta angustia que me domina) marcho triste y melancólico por la Estufa Fría, sintiéndome como un vagabundo mientras trato de apartar esa tentación que me asalta sin piedad, la tentación del salto. (Vila-Matas, Suicidios $\mathbf{1 4}$ )

La ejemplaridad de la historia desprovista de tiempo se presenta, pues, como una quimera para este narrador, en cuyo relato se contraponen y 
entran en conflicto los principios dionisiacos (la dimensión temporal, la infinitud de lo desconocido, la plenitud del ir más allá de los propios límites, la locura, el principio de actuación) y los apolíneos (la dimensión espacial, la limitación, el conocimiento de sí, la calma, el silencio), revelándose estos insuficientes para dotar de una forma artística a la vida. De ahí la insatisfacción de ese artista frustrado y la alternativa del suicidio, no consumado, ante su incapacidad.

Frente a la contención del narrador de "Muerte por saudade", la familia de Horacio se presenta como la abanderada del éxtasis vital y del desenfreno, de la plenitud, lo cual, paradójicamente, termina abocándolos al suicidio, en lo que en el relato se denomina la plenitud suicida. El caso más llamativo en lo que toca a esa existencia exuberante dentro de la familia de suicidas - cuya casuística recuerda, de forma vaga, a la del escritor uruguayo Horacio Quiroga - es quizás el de la tía Clara, quien "poco antes de abrir la llave del gas, dejó una carta al juez en la que le decía que la imposibilidad de frenar el deseo de vivir era la causa directa de su suicidio" (23). Pero el acto suicida, tal y como lo describe el narrador - "un movimiento solitario, alejado de todas las miradas, perpetrado en la sombra y el silencio" (I8) -, se perfila como el reverso de lo que fueron en vida, un punto final de serenidad apolínea a una vita de éxtasis y desenfreno dionisiacos.

La propuesta suicido-escrituraria de Vila-Matas aparece representada, en mise en abyme, en el último de los relatos, "El coleccionista de tempestades". Además de quedar consignada la dimensión apolínea de la empresa en el lema en latín del escudo de armas (Buscamos siempre el lado inmóvil del tiempo), todo el libro puede ser visto como una certera encarnación del invento cilíndrico con las diez sales químicas. Gracias a un efecto óptico, cada una de dichas sales reproducirá "con admirable fidelidad una de las diez tempestades más colosales del siglo" (I68). La equivalencia suicidio/tormenta resulta así evidente. Una vez desprovisto de la linealidad discursiva o de la dimensión temporal, el binomio suicidio/tormenta se consolida como elemento del espacio, como imagen: "diez tempestades, perfectamente seleccionadas, están reproducidas, pienso que con inmejorable acierto, en las sales químicas o graciosos cristales" (I69). El carácter anfibológico del fragmento saca a escena el resultado perseguido: el de la obra perfectamente cerrada que se autoliquida en su propio visionado, el de la perfección de la obra tras el suicidio del autor:

una visión última muy arrebatadora: la perfecta reproducción al unísono de las diez tempestades más activas y feroces del siglo hasta acabar en un efecto óptico por el cual todas las tempestades se superpondrían unas a otra y, bajo la música relajante 
de una canción napolitana y gracias a la fusión de la gran energía de las diez tormentas en la modesta y mínima energía de las tempestades representadas en la parte inferior del bocal transparente, acabarían proyectando el efecto final y mortal durante tantos meses buscado, el efecto definitivo: ese tan esperado rayo colosal que le partiría su alma de inventor y, acto seguido, cerraría la losa de su tumba para toda la eternidad. (I70)

La invocación, en el prólogo, de Alberto Savinio se torna en este momento esclarecedora, por la apología que este realiza en sus textos críticos de las artes plásticas. En efecto, la pintura metafísica de principios del XX reivindica el carácter estable y armónico de la imagen pictórica, esencialmente apolínea, frente a la inestabilidad de otras artes temporales (Saénz 35). Vila-Matas parece apoyarse aquí, como Alberto Savinio en su "Primi saggi di filosofia delle arti", en esa noción de inmovilidad, concebida como proceso liberador:

Las artes en las cuales está implícito el elemento rítmico se inspiran en la idea del tiempo, del movimiento, del devenir, en resumen de la vida. Tal idea no lleva a una noción de estabilidad, porque refleja el destino transitorio al cual está fatalmente conectado todo movimiento. El sentimiento de esa precariedad suscita, por efecto de reacción, el deseo de la estabilidad que llega a ser la más profunda y constante nostalgia de los mortales. Es por ello, que la mente humana contrapone siempre a la noción del tiempo, la del movimiento (noción que se genera en ella a partir de la vida misma), una noción contraria, la noción de la inmovilidad y sobrepone ésta o aquella o, mejor dicho, la noción de la inmovilidad viene a constituir la solución, la meta, el premio (según las diferencias morales de los individuos) de todo movimiento. (Sáenz I32)

De ahí esa vocación en los Suicidios ejemplares por aniquilar el tiempo, por alcanzar la plenitud del movimiento controlado, del viaje sobre el mapa del viajero inmóvil. La imposibilidad de su narración (su inverosimilitud, su inefabilidad) le confiere justamente el carácter ejemplar al suicidio. Así, la muerte por saudade solo adquiere ejemplaridad cuando se desprovee a la nostalgia del elemento temporal (el pasado); cuando hasta el tiempo mismo del salto es eliminado. El discurso cede paso al silencio, imponiéndose lo visual. El suicidio se realiza entonces en la contemplación del cielo infinito de Lisboa; y en lugar de un cadáver, deja una estampa:

Pero no saltaré al vacío, amigo Horacio. Dejaré que me invada toda esa tendencia a recuperar la infancia, toda esa nostalgia por un pasado que, a medida que me acerco al Mirador de Santa Luzía, noto que voy conciliando con el presente, hasta el punto de que tengo la impresión de no estar retrocediendo en el tiempo, sino de 
casi eliminarlo. Me sentaré a esperar, habrá una silla para mí en esta ciudad, y en ella se me podrá ver todos los atardeceres, callado, practicando la saudade, la mirada fija en la línea del horizonte, esperando a la muerte que ya se dibuja en mis ojos y a la que aguardaré serio y callado todo el tiempo que haga falta, sentado frente a este infinito azul de Lisboa, sabiendo que a la muerte le sienta bien la tristeza leve de una severa espera. (24)

La preeminencia en su narrativa de lo visual y la importancia de la mirada, así como la obsesión por la escritura silente, señaladas tanto por Yvette Sánchez como por David Roas, entroncan con esta obsesión por la imagen y la contemplación en los Suicidios ejemplares. Si bien la instauración de esa suerte de reino de la imagen remite en Vila-Matas, como sostiene Ródenas de Moya, a la vanguardia histórica, en especial al surrealismo, el aspecto contemplativo y de aniquilación de lo temporal nos conduciría al lado apolíneo del arte, a su carácter sereno, en la línea de lo que sugiere Nietzsche:

Ante nuestras miradas tenemos aquí, en un simbolismo artístico supremo, tanto aquel mundo apolíneo de la belleza como su sustrato, la horrorosa sabiduría de Isleño, y comprendemos por intuición su necesidad recíproca. Pero Apolo nos sale de nuevo al encuentro como la divinización del principium individuationis, sólo en el cual se hace realidad la meta eternamente alcanzada de lo Uno primordial, su redención mediante la apariencia: él nos muestra con gestos sublimes cómo es necesario el mundo entero del tormento, para que ese mundo empuje al individuo a engendrar la visión redentora, y cómo luego el individuo, inmerso en la contemplación de ésta, se halla sentado tranquilamente, en medio del mar, en su barca oscilante. (57-58)

Lo anterior nos permite ciertamente entroncar la propuesta vilamatasiana con la de Jean Cocteau, que en su trilogía órfica (Le sang d'un poète, I930; Orphée, I950; Le testament d'Orphée, 1960) plasmará su interés por la mitología clasicista, y en particular, por la figura de Orfeo, el artista apolíneo por excelencia. En el relato "Rosa Schwarzer vuelve a la vida" una vigilante de un museo de Düsseldorf, seriamente agobiada por el peso de la existencia, arrastra sus alas de albatros por la grisalla de la cotidianeidad, dispuesta a suicidarse de cualquier modo. Tras rechazar la ingesta de lejía, el salto por la ventana y el gas del horno, el personaje se suicida lanzándose a un cuadro de Paul Klee, El príncipe negro. Dicha tela le enviaba desde hacía un tiempo ciertas señales auditivas para llevarla a la muerte (el tam-tam del país de los suicidas), algo que ella había contrarrestado con la contemplación de otro cuadro de Klee, Monsieur Perlenschwein. El suicidio y posterior des-suicidio de Rosa Scharzer, ha de 
ser entendido, más que como una simple apuesta por la vida, como un atenerse a la ejemplaridad suicida prescrita: la vida (o la muerte) en el cuadro no es posible, porque ha sido promovida por una música, cuya dimensión temporal la desprovee de su perfección. Lo mismo sucede con el movimiento de los colores, la danza de las figuras, la inestabilidad del cuadro. Inferimos que sale del cuadro - en un movimiento, de entrada y salida, que no puede sino recordar a los que tienen lugar en los espejos de los filmes de Cocteau - porque el ideal apolíneo de fijeza espacial que proclamara Nietszche en El nacimiento de la tragedia no se cumple, ya que la sensualidad y la bestialidad de esa muerte de rasgos dionisiacos, con danza delirante y prolongada incluida, atenta contra la ejemplaridad propuesta. Queda así dibujada una figura simétrica, un viaje de ida y vuelta, que, sin embargo, ha logrado acallar la música y ha impuesto la perfección y estabilidad de la quietud: "Inmóviles están ahora el negro del príncipe y el rosa del Monsieur. En el fondo, todo está en perfecto y triste orden" (62). Asistimos, pues, como también sucede en Le sang du poète, al proceso de apolinización de los impulsos vitales dionisiacos, ya sea en la obra de arte o en el artista. Dicho proceso culmina en ese silencio de raigambre netamente apolínea, en el caso del relato de Vila-Matas, y en el suicidio, en el caso del artista de la segunda parte del film de Cocteau, tras el viaje por el espejo.

Por su parte, el suicidio en "El arte de desaparecer" escenifica la muerte del autor. Pero al mismo tiempo esa desaparición supone un dejar a un lado todos los libros sobre el equilibrio para alcanzarlo realmente. Y la calma frente al éxtasis, la muerte en su dimensión apolínea y estática encuentran su lugar en "Las noches del iris negro", donde tiene lugar una apología del "suicidio clásico y sereno, profundamente mediterráneo" (96). La historia de la conjura de los suicidas serenos y calmos, concluye como comenzó, con la apreciación visual de los impulsos auditivos, con la quietud del mar sereno:

Me gusta mucho estar cerca de este mar, nunca debí alejarme tanto de él. Siento ante el oleaje una sensación de libertad sólo comparable a la que percibo ahora al notar que Victoria y yo andamos en la buena compañía de quienes supieron afrontar la muerte con serenidad antigua. A éstos, hace unos instantes, los hemos llevado silenciosamente a nuestro interior y hemos llenado sus vacíos con nuestra propia sustancia, y hemos pasado a ser ellos. Y yo voy andando por la playa de Port del Vent bajo la lluvia, y me digo todo esto y escucho y contemplo el oleaje y me digo que sí, que toda la noche cabe en una mirada de color iris negro, en una sola y quieta mirada de sosiego. (IOI-2) 
Del mismo modo, el trazado geométrico y los ejes de simetría tan caros a Opicinus se concretan en distintos relatos, como en el citado caso de "Rosa Schwarzer vuelve a la vida", donde, como Orfeo ante el espejo, esta entra y sale del cuadro. O en "La hora de los cansados", donde el personaje deshace el camino hecho siguiendo su propio rastro de sangre, mientras un kamikaze hace saltar en pedazos la catedral. En "Me dicen que diga quién soy", las simetrías vienen de la mano de esos cuadros con vocación realista por los que aboga el diablo, así como de la inversión de los nombres y los títulos de los cuadros, que, primero en forma recta y después invertida, dan palíndromos que invitan a transitar por ellos cruzando un imaginario eje de simetría. La repetición obsesiva del leitmotiv suicida, así sea con variantes, la idea del dibujo y la omnipresencia de la locura nos devuelve a Marcel Réja y su reflexión de 1907 sobre el arte a manos de los locos: "Le fou, inexpérimenté dans l'art du dessin, refuse de se hasarder aux formes complexes où ses maladresses seraient trop flagrantes. ... Il se contente de répéter à l'infini le même motif, d'ailleurs fort simple et emprunté à la géométrie" (Meunier 29). A caballo entre la geometría y la geografía, los Suicidios ejemplares representan, en última instancia, una cartografía literaria e irónica del suicidio desprovisto este de todo atisbo de arrebato, desesperación o tragedia, pero también de realidad -, en la que, no solo los personajes, sino también el lector pueden proyectarse para cumplir con la máxima apolínea del conócete a ti mismo, adentrándose en ese espejo deformante que es el espacio de la escritura.

Hemos visto, pues, que en los Suicidios ejemplares se concretan y se ponen en escena algunas de las consideraciones vilamatasianas acerca de la espacialidad de la escritura, dispersas, de un modo u otro, en el resto de su obra. Vila-Matas recurre aquí a la repetición insistente de un motivo (el suicidio), no únicamente con la intención de elaborar un inventario suicida, ni con la sola pretensión de ahondar en cuestiones de índole existencial. Fiel al principio que rige la mayor parte de sus textos problematizar metaliterariamente la frontera que separa la ficción de la realidad - el tema suelta amarras con respecto al nivel extradiegético para replegarse en lo meramente textual. A partir de ahí y del vínculo que el autor establece entre suicidio y silencio, el leitmotiv servirá de eje en torno al cual construir una teoría - más o menos deshilvanada, pero una teoría a fin de cuentas - acerca de la importancia de lo espacial en la literatura y de la necesidad de que esta, desprovista del transcurrir temporal característico del discurso, se aproxime a la ucronía propia de las artes plásticas. Desde el prefacio hasta el epílogo, pasando por cada uno de los diez relatos que integran el volumen, se incide en mayor o menor medida en la vocación espacial que exhibe una escritura que aspira, acaso 
quiméricamente, a desterrar el fluir del tiempo. Un destierro que, atendiendo al conjunto de su obra, puede ser visto como trasunto del desapego por la historia y por la progresión del relato que caracteriza las obras de Enrique Vila-Matas - y que en el volumen analizado ejemplifica a la perfección la narradora de "Los amores que duran toda una vida" -, en lo que se conoce como su proverbial asco de relatar. Se trataría, así, de una apuesta por la victoria de la digresión y del estilo sobre la trama que avanza, en eso que algunos han dado en llamar el suicidio de la literatura.

University of Miami

\section{NOTAS}

I Irene Zoe Alameda establece una certera gradación entre Historia abreviada de la literatura portátil y Bartleby y compañía, pues, como sostiene, "el espíritu que anima a los shandys es la reducción al máximo de la escritura por amor a la misma, lo que puesto en práctica da como resultado la desaparición de la literatura, el silencio, la obra inexistente de los bartlebys" (54). Una interpretación interesante de este texto es la que hace Marcos Eymar, quien, a la luz de Bartleby, la formula della creazione, de Giorgio Agamben, equipara el silencio a la creación, la obra inconclusa a la terminada ("L' œuvre").

2 En El nacimiento de la tragedia (Die Geburt der Tragödie, 1886), Friedrich Nietzsche analiza la presencia en las artes de dos principios opuestos, lo apolíneo y lo dionisíaco. Si en la tragedia griega ambos principios estaban sabiamente integrados, con posterioridad esto no será así, primando con frecuencia uno u otro. La dicotomía ha sido ampliamente utilizada como principios de estructuración del campo estético (Llinares Chover).

3 Marcos Eymar ha apuntado ese cambio: "Alors que, avant Bartleby et compagnie, l'auteur semble davantage concerné par l'aspect comique et mystificateur de la 'fausse mort-événement', ce livre ouvre une nouvelle période qu'on pourrait qualifier de 'blanchotienne', où l'écriture devient un moyen d'explorer cette 'deuxième mort' qui n'est pas tant la conclusion de la vie que l'origine fascinante de l'œuvre et du langage." ("Les derniers").

4 Es ya un lugar común el considerar a Enrique Vila-Matas como el más latinoamericano de los escritores españoles. Entre otros, Francisca Noguerol ha apostado recientemente por subrayar algunos de los vínculos del autor catalán con distintos escritores de Hispanoamérica, en lo que ha dado en llamar lecturas casuales. Aunque no es nuestra finalidad, en este ensayo establecemos comparaciones, en lo que respecta al tratamiento del suicidio, entre la práctica de Vila-Matas y la de algunos escritores del continente con los que mantiene estrechos vínculos. 
5 Este será, sin embargo, el enfoque de Maria Torres Ponce y Francisco Javier Romero Luna en su análisis de "Rosa Schwarzer vuelve a la vida".

6 Al vincular suicidio y absurdo es una cita obligada el texto de Camus, Le mythe de Sisyphe (1942), subtitulado justamente Essai sur l'absurde. No es Vila-Matas el primer escritor que, ante la recomendación de este de abordar el tema suicida con una adecuada combinación de lirismo y de perogullada (Camus i8), añade la ironía y el humor como elementos distanciadores para evitar la caída en lo melodramático. Por ejemplo, son varios los textos periodísticos de Gabriel García Márquez - en cuyo tratamiento del suicidio se deja sentir la huella del filósofo francés - que presentan ciertas concomitancias con los de Vila-Matas en lo que respecta a la ridiculización, la recurrencia al absurdo y la construcción de escenas delirantes al escribir el suicidio (véase Quesada Gómez, "Gabriel" 9I-95). En la línea de otros escritores de la literatura del absurdo, Vila-Matas apuesta por cargar de sentido al absurdo, como reitera en el prefacio a Aunque no entendamos nada.

7 Cristina Oñoro Otero analiza el uso de los mapas en la construcción de una poética de la ficción por parte de Vila-Matas y cómo estos sirven para marcar las distintas etapas de su producción: "de la literatura como experimentación lúdica, durante los años setenta y comienzos de los ochenta, a la literatura como espacio en el que desplegar una geografía mental, en la primera década del siglo XXI. Y en el centro de ese viaje, otros dos momentos esenciales: la literatura como construcción de mundos ficcionales, a finales de los años ochenta y durante los noventa, y como espacio de desaparición en el cambio de siglo ("Locuras" 89). Por su parte, Alfredo Aranda Silva subraya el uso que Walter Benjamin hará de esta misma frase, "Viajo para conocer mi geografía", en su Libro de los pasajes (199).

8 Puede verse al respecto el trabajo de Roux y Laharie.

9 Túa Blesa analiza justamente en sus trabajos la recurrencia a la fagocitación de otros textos por parte de Vila-Matas en Historia abreviada de la literatura portátil, en lo que constituiría una suerte de plagio lúdico con modificaciones que se sitúa "entre la expoliación y el homenaje admirativo" (48).

Io Esa sucesión de asociaciones que aúnan ideas dispares es una constante en la obra de Vila-Matas, como apunta José María Pozuelo Yvancos a propósito de Historia abreviada de la literatura portátil (169).

1I Frente a la categorización de posmoderno, tanto Pozuelo Yvancos como Ródenas de Moya han insistido en subrayar los vínculos de Vila-Matas con la vanguardia histórica, reivindicando así el doble enraizamiento de su narrativa. Para una síntesis de la cuestión, véase Castro Hernández.

12 Véase el relato de los tres suicidios de Rigaut (Papiers I07-IO9), publicado originalmente en el número I7 de Littérature (diciembre de 1920), donde humor, suicidio y absurdo se entremezclan. Remi dedica un apartado de su libro a "humor y suicidio" (315-330), donde se incluye el caso de Rigaut y su 
proyecto de una Agence générale du suicide (317-318), que no será publicado hasta 1959 .

13 En lo que respecta a la ejemplaridad de estos suicidios, el propio autor ha manifestado su deuda, no con Cervantes, sino con Max Aub y sus Crímenes ejemplares (1957) (Gabastou 79).

14 La traducción de las cartas a Pessoa en esta edición está a cargo de Simone Biberfeld.

OBRAS CITADAS

A LAMEDA, IRENE ZOE. "El diálogo supratemporal frente a la impostura literaria. Claves para descifrar la obra de Enrique Vila-Matas". Cuadernos de narrativa. Enrique Vila-Matas. Eds. Irene Andres-Suárez y Ana Casas. Madrid: Arco/Libros, 2007. 49-63.

ALVARADO SILVA, MARÍA SELENE, Y DiANA ISABEL HERNÁNDEZ JUÁREZ. "La plenitud suicida y literaria en 'Muerte por saudade', de Enrique Vila-Matas. Géographies du vertige dans l'oeuvre d'Enrique Vila-Matas. Eds. Alain Badia, Anne Lise Blanc y Mar Garcia. Perpignan: Presses Universitaires de Perpignan, 20I3. I5I-66.

A N R RÉs, RAm Ó N. Historia del suicidio en Occidente. Barcelona: Península, 2003.

ARANDA SILVA, ALFRED o. "Morfología de la geografía literaria en el artículo ensayístico de Enrique Vila-Matas". Géographies du vertige dans l'oeuvre d'Enrique Vila-Matas. Eds. Alain Badia, Anne Lise Blanc y Mar Garcia.

Perpignan: Presses Universitaires de Perpignan, 2013. 199-210. B LA NCH о T, MA U R ICE. L'espace littéraire. Paris: Gallimard, 2005. B LESA, T ÚA. "Un fraude en toda regla. Historia abreviada de la literatura portátil 2". Tropelías: Revista de Teoría de la Literatura y Literatura Comparada I2-I4 (200I-2003): 45-58.

camus, albert. Le mythe de Sisyphe. Paris: Gallimard, 2006.

Castro Hernández, Olalla. "Enrique Vila-Matas o cómo habitar el filo del abismo". Sociocriticism 31.I (2016): 49-80.

DA H L, JU L IE M. "Suicidal Spaniards in Moody Portugal and Other Helpful Stereotypes: Imagology and Luso-Hispanic Cultural Studies." Arizona Journal of Hispanic Cultural Studies 15 (20II): 23-40.

de sá-Carneiro, mario. Cartas de Mário de Sá-Carneiro a Fernando Pessoa. Ed. Manuela Parreira da Silva. Lisboa: Assírio \& Alvin, 20oI.

—. Poésies complètes. Trad. de Dominique Touati y Michel Chandeigne. Paris: La Différence, 2007.

e n R I U U, Á LVA Ro. "Suicidios ejemplares". Vila-Matas portátil. Un escritor ante la crítica. Ed. Margarita Heredia. Barcelona: Candaya, 2007. 8I-84.

E YMAR, MARCos. "Les derniers mots. Fin de vie et fin de la littérature dans l'œuvre d'Enrique Vila-Matas". Temps Zéro 3 (2010). S. pag. Web. 
—. "L'œuvre comme possibilité: pour une étude comparée de la littérature négative". Trans- Revue de Littérature Générale et Comparée I (2005). S.pag. Web.

florencia zaldívar, Jesús humberto. "Enrique Vila-Matas y la apacible mirada del suicida". Enrique Vila-Matas: Los espejos de la ficción. Ed. Felipe Ríos Baeza. México: Ediciones Eón, 20I2. 151-66.

GaB AST OU, A NDRÉ. Vila-Matas, pile et face. Paris: Argol Éditions, 2010.

Ga RCiA, Mar. "Préface". Géographies du vertige dans l'œuuvre d'Enrique Vila-Matas.

Eds. Alain Badia, Anne Lise Blanc y Mar Garcia. Perpignan: Presses

Universitaires de Perpignan, 2OI3. II-22.

G RISE, Y L LANDE. Le suicide dans la Rome antique. Montréal/Paris: Bellarmin/Les

Belles Lettres, 1982.

ко CIANCICH, Vlad y. Cuando leas esta carta. $2^{2}$ ed. Buenos Aires: Planeta, I999.

LIVAK, LEONID. "The Place of Suicide in the French Avant-Garde of the Inter-War

Period". The Romanic Review 91.3 (2000): 245-62.

L L ED Ó, EMILIO. El silencio de la escritura. $2^{\underline{a}}$ ed. corregida y aumentada. Madrid:

Espasa-Calpe, 1998.

llinares chover, joan. "Apolo y Dionisio como principios de estructuración del campo estético". Cuadernos de Filosofía y Ciencia I (1982): 19-32.

masoliver Ródenas, JUAn antonio. "Una coreografía de la destrucción". Vila-

Matas portátil. Un escritor ante la crítica. Ed. Margarita Heredia. Barcelona:

Candaya, 2007. 85-89.

me unier, Pa ul. Marcel Réja. L'art chez les fous, le dessin, la prose, la poésie. Paris: Société du Mercure de France, 1907.

M I N IS, G E O R G E. Histoire du suicide: la société occidentale face à la mort

volontaire. Paris: Fayard, 1995.

NIETZSCH E, FRIEDRICH. El nacimiento de la tragedia. Madrid: Alianza, I995.

NO GUER OL JIMÉNEZ, FRANCISCA. "Lecturas casuales: Enrique Vila-Matas y sus vínculos transatlánticos". Atenea 514 (2016): 169-88.

oñ Oro o tero, Cristina. Enrique Vila-Matas. Juegos, ficciones, silencios. Madrid:

Visor, 2015 .

—. "Locuras cartográficas: los mapas para (no) perderse de Enrique Vila-Matas". Géographies du vertige dans l'ouvre d'Enrique Vila-Matas. Eds. Alain Badia, Anne Lise Blanc y Mar Garcia. Perpignan: Presses Universitaires de Perpignan, 2OI3. 73-92.

POZUe Lo yVAnCos, jo SÉ maría. Figuraciones del yo en la narrativa: Javier Marías y E. Vila-Matas. Valladolid: Universidad de Valladolid, 20 IO.

QUESADA GÓMEZ, CATALinA. "Absurdamente, más vale persistir. Onetti frente al suicidio". Letral 2 (2009): 38-5I. 
- "Asesinos tímidos: teoría y práctica del suicidio en la obra de Ricardo Piglia". Homenaje a Ricardo Piglia. Ed. Teresa Orecchia Havas. Buenos Aires: Catálogos, 20I2. 233-50.

—. "Escenografías suicidas de Alejandra Pizarnik: hacia la elipsis". Letral 8 (2OI2): 44-55.

—. "Gabriel García Márquez: historia de un suicidio". Gabriel García Márquez, la modernidad de un clásico. Eds. José Manuel Camacho Delgado y Fernando Díaz Ruiz. Madrid: Verbum, 2009. 86-III.

Rig au T, JAC Q u es. Agence générale du suicide. Paris: Jean-Jacques Pauvert, 1959.

-. Papiers posthumes. Paris: Au Sans Pareil, I934.

ROAS, DAVID. "El silencio de la escritura (a propósito de Bartleby y compañía)". Cuadernos de narrativa. Enrique Vila-Matas. Eds. Irene Andres-Suárez y Ana Casas. Madrid: Arco/Libros, 2007. I4I-52.

RÓDENAS DE MOYA, DOMINGo. "La novela póstuma o el mal de Vila-Matas". Cuadernos de narrativa. Enrique Vila-Matas. Eds. Irene Andres-Suárez y Ana Casas. Madrid: Arco/Libros, 2007. 153-72.

rodríguez de la Flor, Fernando. Biblioclasmo. Por una práctica crítica de la lecto-escritura. Salamanca: Junta de Castilla y León, 1997.

roux, guy, y muriel laharie. Art et folie au Moyen Age. Aventures et énigmes d'Opicinus de Canistris (I296-vers 135I). Paris: Le Léopard d'Or, 1997.

SÁenz, ol Ga. Giorgio de Chirico y la pintura metafísica. México: UNAM, 1990.

SÁ NCH EZ, Yvette. "De miradas indiscretas y textos invisibles". Cuadernos de narrativa. Enrique Vila-Matas. Eds. Irene Andres-Suárez y Ana Casas. Madrid: Arco/Libros, 2007. 65-75.

torres ponce, maría, y francisco ja vier romero luna. "Muerta en vida. La búsqueda de la muerte en 'Rosa Schwarzer vuelve a la vida'”. Enrique VilaMatas: Los espejos de la ficción. Ed. Felipe Ríos Baeza. México: Ediciones Eón, 2OI2. I8I-96.

VALLS, FER RAN Do. "Don Quijote de las Azores o el último novísimo". La realidad inventada. Análisis crítico de la novela española actual. Barcelona: Crítica, 2003. $302-5$.

vila-matas, enRiQue. Aunque no entendamos nada. Santiago de Chile: JC Sáez Editor, 2003.

-. Bartleby y compañía. Barcelona: Anagrama, 2000.

-. Doctor Pasavento. Barcelona: Anagrama, 2005.

-. Exploradores del abismo. Barcelona: Anagrama, 2007.

-. Historia abreviada de la literatura portátil. Barcelona: Anagrama, 1985.

-. El mal de Montano. Barcelona: Anagrama, 2002.

-. Suicidios ejemplares. Barcelona: Anagrama, I99I. 